\title{
Personalized Learning Evaluation Model based on Cluster Analysis of Large Education Data
}

\author{
Sannyuya Liu ${ }^{1}$, wenyuan Wang ${ }^{2}$ \\ ${ }^{1}$ National Engineering Research Center for E-Learning, Central China Normal University, \\ wuhan, china \\ ${ }^{2}$ Collaborative \& Innovative Center for Educational Technology, Central China Normal University, \\ Wuhan, China
}

Keywords: Big Data; Learning Analytics; Data Mining; Co-Word Analysis; Social Network Analysis

\begin{abstract}
As the new trend of information technology development, big data has been infiltrated into all walks of life and thus become an important cause of formation. At the big data era of data analysis driving education and reforming teaching, the education field also reserves massive data with extensive application value. On the basis of education data mining, learning analytics technology and other key technology analysis on bid education data, combined with the co-word analysis, education blogs and other social network education data, build the relevant learning analytics and data mining model in education field, explore the relevant relations among the education variables, practice the education application of big data and provide sufficient decision-making support service for the education teaching, to facilitate the education teaching reform and innovation.
\end{abstract}

\section{Introduction}

As the new trend of information technology development, the bid data has infiltrated into all walks of life, become an important driving factor and raised the surge in industry reform. Following constant promotion of our education information level, more and more learning management system have been applied in the education field, accompanying with gradually increase of digital learning information and student information, as well as massive growth of education data, causing the education management, education service, teaching research, education evaluation and other field also in the face of big data problem. Hence, the age of bid education data is already coming quietly. "As the explosive increase of education information and innovative development of relevant data process technology have become new view focus for the people, how to utilize and analyze these data information not only have influences in information exchange, knowledge transmission and learning effect, but also influencing the teaching decision making and learning mode optimization, which has already become an aspect concerned by the education workers and learners at present.

\section{Education Analysis under Big Data}

\section{Big data}

In virtue of omnipresent sensing equipment and computing power, the big data analyzes and excavates the complex network data of real world, virtual world and virtual-real fusion world, to realize the behavior judgment and decision making. Following the application of various learning management system, course management system and network interactive platform in education field, various learning behaviors, learning states and education data will massively increase, and the age of bid education data is already coming. The big data enables the education information to become a digital existence able to be captured, quantized and transmitted, enables the education process investigation to be possible, and finds the relationship between the teaching and learning 
through the real data. A reform takes place stealthily in the education.

Big data provides technological basis for the access of massive education data, but the original education data is just the basis of big education data, and the data can be transformed to be the information only by making education data mining on various data, building the learning analytics model, finding the relationship among education variables and giving relevant meaning to the data; the information after further analysis and synthesis forms the knowledge; finally by practical application, the knowledge is lifted to the wisdom level. [8] Therefore, the education data mining and learning analytics technology is the key technology of big education data.

\section{Education data mining}

Education data mining is to comprehensively apply the mathematical statistics, artificial intelligence, machine learning, data mining and other technologies and methods, make analysis processing on the original education data, and make correlation analysis on the learning result, learning content, learning resource and teaching behavior of learner by building the data models, so as to effectively predict the future learning trend of the learner. It offers support to the education workers, learners, parents of students, education teaching researcher and teaching software developer, to achieve the benign interaction of education resources in education system, and finally achieve the purpose of improvement learning. The specific education data mining process is as shown in the Figure 2.

\section{Learning analytics}

The research object of learning analytics is the students and their learning environment, with the purpose of finding potential problems by analyzing and modeling the massive education data, to optimize and understand the learning, and predict the learner's progress and performance in the learning. Obviously, the learning analytics technology is to center on various information data produced during the learning process, interpret these data with various mathematical modeling, explore the learning process and scenarios according to the result data and analytic information, and further find the learning rule, to provide corresponding feedback for the teaching optimization and completion, and constantly facilitate the learner's learning. Take advantage of data mining, data interpretation and data modeling, the learning analytics technology collects, stores, analyzes and display mass data information accumulated in the learning platform, evaluates, predicts and intervene the learners' learning behavior by using analysis measurement result, and customizes more efficient education for individualized students, so as to improve and promote the teaching and learning quality and efficiency.

In addition to two key technologies of big education data (learning analytics and data mining), in recent years, Mooc, Micro Learning Resource, Flipped Classroom, social network software, cloud computing, Moodle and other network learning open-source platforms and WEB2.0 technologies all can be brought into the technology category of big education data.

\section{Data Mining and Learning Analytics Contribute to the Teaching Decision Making and Evaluation}

\section{Data mining and learning analytics}

Big education data records the teaching process, finds new knowledge, creates greater education value, facilitates and optimizes the teaching strategy and evaluation. At the mobile internet age, the knowledge centering on the students, as every student's intelligence feature and absorption are not the same. The mobile internet supports the learning centering on the students, to break through the tradition that all people have not to listen a same teaching content within specific forty five minutes in the uniform class. The emerging education technology and resource enable the education centering on the learner more, and enable the realization of batched education to individualized education to be possible; the teachers' education thought also turn from the macroscopic group education to the microcosmic individualized education way, facilitating the implementation of individualized education with learner as center, and further enabling the individualized quality education to be possible.

Technically, any data trace left by the learner on the internet and other media all can be analyzed, 
of which the relevant learning feature, hobbies and interest, behavior tendency, and state information relevant to the education teaching of learner hidden behind the data can be seen. In this sense, the future education development direction is using learning analytics, data mining and other big data technology to realize the accurate individualized education. With integrated analysis on massive data in education teaching by big data, combined with the altitude, behavior, behavior background and other factors, it is able to find the student thought, behavior and mentality change, analyze the features of every student, and make correct evaluation on some student accurately with combination of the student's overall performance and other factors distribution, and finally enabling the education for every student to be built on the basis of analysis on the past behavior data, so as to truly break through the dilemma that "we have to admit that we get very little knowledge on the students" under the traditional technology background.

The big data technology is beneficial to extract and analyze various data in the classroom teaching plan, classroom teaching evaluation and classroom video resource of teacher, so as to provide important basis for predicting and processing the teaching behavior and learning psychology, offer relatively comprehensive and complete information to the teaching evaluation and overcome the regret of strong evaluation subjectivity. Therefore, the teaching evaluation will not be an experimented one, but is the "induction" based on the big data, to be more convincing and creditable, realizing the objective, fair, scientific and correct teaching evaluation.

Micro Learning Resource and Flipped Classroom teaching are beneficial to reconstruction of individualized learning mode

The future education will be more and more individualized under the support of big data technology; the teaching application of Mooc, Micro Learning Resource and Flipped Classroom is beneficial to build the individualized learning environment; the standardized customization of digital course resource achieves the self organizational learning of students for learning content; the online learning enables the school education and teachers to turn to the individual students more and pay attention to the individualized cultivation of the learner; the teachers achieve the transformation from the teacher to the learning assistant and undertake the support service and collaborative communication of learning more. The individualized learning mode pays more attention to the communicative interaction, individualized service and flexible teaching paradigm between the teachers and students, the students and students, the students and education media.

Micro Learning Resource achieves the solidification to the fragments of knowledge, and the mobile internet enables us to make full use of fragment time. Not only that, our utilization on fragment time every time can be of very high efficiency. Therefore, the learning system is aware of your learning condition and knows how to make your learn more efficiently.

In the traditional education, everyone is in a closed living room, with every class stipulated at 45min. However, at present, the mobile internet enables the students can communicate with the learners all over the world, to achieve the knowledge learning offline and knowledge transmission online, completely turn upside down the traditional teaching structure, and enable the knowledge instruction mode stressing on knowledge transmission and defining learning by teaching to gradually give way to the integrated exploration mode stressing on problem center and focusing on learning, so as to build new teaching paradigm.

\section{Empirical Analysis on Application of Key Technology of Big Data in Education}

The education future brought by the big data, not only express a concept and social intuition, but also a kind of education reform and social action. Supported by the big data technology, the education is not just the single social science for concept communication and experiment inheritance, but becomes the empirical science relying on the education behavior. At the big education data, because of the arrangement of teaching experiment, the design of education time and space, construction of learning scenarios, creation of education environments, collection of education data, and decision making on education managements, which only can rely on the concept inspiration and experiment, can be recorded and tracked in data form, and truly become a kind of behavior science supported by data. 
A mass of learning state data is accumulated for the extensive application of big data technology in the education teaching practice. How to make data speak to reveal the education phenomena nature behind the education data and provide the constructive solutions for the education decision making and policy formulation, we will make empirical analysis by utilizing application case of two key big data technologies (data mining and learning analytics) in teaching field, to provide reference and enlightenment for the education application of the data mining, learning analytics and other big data technologies.

\section{Co-word analysis based on education data mining}

The big education data technology facilitates the professional development of teachers, of which these two have a certain correlation and many domestic literatures have made deep research on these two. We extract the keyword frequency relevant to the professional development of teachers and big education data occurred on the CNKI, EBSCO, Springerlink and other domestic and overseas periodicals for 10 years, build the co-word analysis matrix by utilizing the content analysis, text analysis and other methods, make analysis and calculation through the Ochiia similarity coefficient method to transform the co-word matrix to the correlation matrix, further build the dissimilarity matrix based on the correlation matrix, analyze by applying the multi-dimension analytical method, and form knowledge pedigree chart for professional development of teachers under the big education data background, so as to provide the good decision-making guidance for the teacher application of big education data.

The education data mining and co-word analysis well shows the knowledge pedigree chart for professional development of teachers under the big education data background, and more definitely explain the influence of big education data in the professional development of teacher and the correlation between these two, so as to provide the efficient guidance and suggestion for the professional development of teachers under the big education data background.

\section{Education blog learning analytics based on social network analysis}

Social network analysis can analyze the correlation between the individual learning behavior and learning actor in the network group and group influence, and evaluate the network attribute through relevant social network analysis software and by utilizing the distance, density and centrality, sociogram and other concepts, which is a kind of visual and strong convincing method and means in the social structure relation research. Under the view of big education data, the learning analytics technology gets more and more attention; as a kind learning analytic method, the social network analysis can make deep mining on the massive procedural data recorded by network learning platform, course management platform and network log, and find the learner's learning behavior and social interaction feature in the network learning, so as to provide the decision-making guidance and service support for the network learning.

In order to make education data learning analytics by utilizing the social network analysis, we choose a professional development training class of primary and middle school teachers as the sample data. With the excellent course by Huzhou University - Education Technology Basis as the network platform, by analyzing the participation activity of training teachers' education blog group on the course website, selecting the education blog communication of 20 teachers in the training class, collect the network log data, and regulate that the posting, link, reply and recommendation of blog are recorded as the network communication.

\section{Summary}

Two key technologies of big data - the learning analytics and data mining, have become the hot spots and trends of education research. The data mining can make statistics, analysis, synthesize and reasoning from micro to macro level for the education data, guides the solution of actual education teaching problem and finds the correlation and rule among the education phenomena, so as to better make education prediction and implement the education decision; the learning analytics not only can provide high-quality individualized learning experience for the students, but also can improve the teaching way of education workers, perfect and optimize the teaching process, truly enable the teaching practice activities to focus on the micro individual, and realize the individualized learning 
and individualized support service of education in a real sense, so as to facilitate the education fairness.

\section{References}

[1] Lv, Z., Tek, A., Da Silva, F., Empereur-Mot, C., Chavent, M., \& Baaden, M. (2013). Game on, science-how video game technology may help biologists tackle visualization challenges. PloS one, 8(3), e57990.

[2] Lv, Z., Halawani, A., Feng, S., Li, H., \& Réhman, S. U. (2014). Multimodal hand and foot gesture interaction for handheld devices. ACM Transactions on Multimedia Computing, Communications, and Applications (TOMM), 11(1s), 10.

[3] Lv, Z., Halawani, A., Feng, S., Ur Réhman, S., \& Li, H. (2015). Touch-less interactive augmented reality game on vision-based wearable device. Personal and Ubiquitous Computing, 19(3-4), 551-567.

[4 Lv, Z., Li, X., Zhang, B., Wang, W., Zhu, Y., Hu, J., \& Feng, S. (2016). Managing big city information based on WebVRGIS. IEEE Access, 4, 407-415.

[5] Zhang, Z., Ou, J., Li, D., \& Zhang, S. (2017). Optimization Design of Coupling Beam Metal Damper in Shear Wall Structures. Applied Sciences, 7(2), 137.

[6] Shen, W., Li, D., Zhang, S., \& Ou, J. (2017). Analysis of wave motion in one-dimensional structures through fast-Fourier-transform-based wavelet finite element method. Journal of Sound and Vibration, 400, 369-386. 